\title{
Evaluation the Expression of Efflux Pump Genes "Tap \& P55 in Mycobacterium Tuberculosis Clinical Isolates in Fars, Iran
}

\section{Fardis Khoob}

shiraz university of medical sciences

Milad Shahini Shams Abadi

shahrekord university of medical sciences

Nahal Hadi ( $\square$ nahalhadi.shz@gmail.com )

Shiraz University of Medical Sciences Medical School

Farzaneh Avazzadeh

shiraz university of medical sciences

\section{Zahra Zarei}

shiraz university of medical sciences

Research article

Keywords: Mycobacterium tuberculosis, resistance, efflux pumps, rifampin, qRT-PCR

Posted Date: November 23rd, 2020

DOI: https://doi.org/10.21203/rs.3.rs-107737/v1

License: (c) (i) This work is licensed under a Creative Commons Attribution 4.0 International License. Read Full License 


\section{Abstract}

\section{Background}

The increasing drug resistance in Mycobacterium tuberculosis isolates has become a global problem for tuberculosis therapy programs. Genetic mutations in rifampin (RIF), one of the key drugs in the treatment of tuberculosis are main mechanism of resistant to this drug in M. tuberculosis. Absence of mutation in target genes, other mechanisms such as efflux pump suggests possible role of drug resistant.

The objective of this study was to find out mutations in $r p o B$ genes in rifampin resistant isolates and to compare the expression level of tap and $p 55$ efflux pump genes in non mutated isolates, mutated isolates in $r p o B$ genes and susceptible isolates.

Methods

In this study, antimicrobial sensitivity test on first line drugs was performed on 200 M. tuberculosis isolates, obtained from TB center in Shiraz (IRAN) and genetic mutations were evaluated in $r p o B$ gene in RIF resistant isolates by multiplex PCR, followed expression level evaluated by Real-time PCR.

\section{Results}

out of the 200 isolates tested, 23 (34.33\%) showed resistant to RIF. 12 of 23 RIF resistant isolates have mutation in $r p o B$ gene, and frequency of mutations in codons 516, 526 and 531 were 3 (25\%), 4 (33.33\%) and $5(41.67 \%)$ respectively.

The expression level of tap and $p 55$ genes was considerably higher in resistant isolates which had no mutation compared to the expression level of genes in the isolates which had mutation in target genes.

\section{Conclusion}

The accumulating data suggest the probable role of efflux pump in $M$. tuberculosis drug resistance, the validation of data needs further phenotypic assays of these pumps.

\section{Background}

Tuberculosis (TB) is a deadly infectious disease which remains one of the most important health problems in world wide [1].

According to the World Health Organization (WHO) reports in 2019, there were 7 million new cases of TB and 1.2 million death caused by TB in 2018 [2].

The increasing prevalence of drug resistant in Mycobacterium tuberculosis (MTB) strains is a major challenge to the control and treatment of TB. One of the forms of drug resistance tuberculosis is multidrug resistant tuberculosis (MDR-TB) (strains resistant to at least two first-line drugs, namely, 
isoniazid (INH) and rifampin (RIF)), which emergence of MDR-TB are major problem to management of TB $[3,4]$ and factors such as poor drug quality, inappropriate administration of anti-TB drugs and inadequate treatment regimens, inappropriate and incomplete drug use by the patient and previous treatment of TB are the most important factors in increasing the prevalence of drug resistant strain [5].

RIF is one of the key and important first line antibiotics, which is used together with INH as the main antiTB regimen. Since rifampin resistant $M$. tuberculosis isolates are often also resistant to INH and monoresistance to rifampin is rare, therefore, rapid identification of rifampin-resistant isolates is important because rifampin resistance is a marker for MDR-TB, which is a major barrier to the treatment of TB [6].

RIF binds to the $\beta$-subunit of the RNA polymerase and inhibits elongation of mRNA. The main mechanism of resistance to rifampin is through the mutation in the $r p o B$ gene, which encodes the $\beta$ subunit of the RNA polymerase $[7,8]$, and according to previous studies, the most frequently mutations in RIF-resistant clinical isolates, occur in the region of 81 base pairs of $r p o B$ gene is called the Rifampin resistance determining region (RRDR), and mutations in codons 531, 526 and 516 are the most commonly reported mutations in this region However, roughly $5 \%$ of $M$. tuberculosis clinical isolates resistant to RIF have no mutation in the $r p o B$ gene, and it increases the possibility of other mechanisms, such as activity efflux pumps, in the emergence of drug resistance $[9,10]$.

The efflux pumps are membrane proteins that can remove various substrates, including drugs, from the cell $[11,12]$. The first efflux pump known in Mycobacteria was LfrA in Mycobacterium. smegmatis, which confer resistance to different compounds including ethidium bromide, acridine, fluoroquinolones, and some quaternary ammonium compounds [10]. The bacterial efflux pumps are divided into 5 families: 1the major facilitator superfamily, 2- the small multidrug resistance, 3- the resistance nodulation cell division, 4- the multidrug and toxic compound extrusion, which use proton motive force and 5- the ATP binding cassette superfamily, which uses ATP as an energy source to remove drugs from the cell $[13,14]$. Few studies to date have investigated the role and the extent of the expression of the efflux pump genes in the development of drug resistance in M. tuberculosis clinical isolates and most studies have investigated the efflux pumps genes by using of laboratory strains (Mycobacterium bovis, Mycobacterium smegmatis) and the transfer of hypothetical efflux pump genes to the strains listed as hosts and the use of inhibitors of efflux pumps [15]. Considering the high prevalence of $M$. tuberculosis and the increased drug resistant strains, as well as the importance of rifampin as the first line antituberculosis drug, it is important to study the mechanism of resistance to the drug mentioned in the isolates of $M$. tuberculosis. The aim of this study was to investigate the prevalence of mutations in codons 516,526 and 531 of the rpoB gene in $M$. tuberculosis isolates, and to determine the expression level of the two efflux pumps genes Rv1410c ( $p 55)$ and Rv1258c (tap) and compare their expression level in RIF resistant $M$. tuberculosis clinical isolates had mutation in the $r p o B$ gene, RIF resistant isolates had no mutation in the $r p o B$ gene and also in the drug-susceptible isolate. Both selected gene were selected from the MFS family and based on previous studies [10, 14]. 


\section{Methods}

\section{Isolation and drug susceptibility testing:}

In this study, 200 M. tuberculosis isolates were obtained from TB center of shiraz and molecular assay were done to confirm MTB isolates and confirmed strains were included this study.

Antibiotic susceptibility test against first-line drugs was performed on MTB isolates by the proportional method on the Lowenstein-Jensen medium according to the WHO recommendation. The concentrations of tested anti tuberculosis drugs were as follows: INH $0.2 \mathrm{mg} / \mathrm{mL}$, RIF $1.0 \mathrm{mg} / \mathrm{m}$, streptomycin (STR) 2.0 $\mathrm{mg} / \mathrm{mL}$ and ethambutol (EMB) $5.0 \mathrm{mg} / \mathrm{ml}$.

\section{DNA extraction:}

Genomic bacterial DNA was extracted from MTB isolates by DNA extraction kit (QIA Gen). To determine the DNA concentration in the extracted specimen, the optical absorption at 260 and $280 \mathrm{~nm}$ wavelengths were measured by spectrophotometer, if the absorbance ratio of 260 to 280 nanometers was more than 1.8 , then it was considered appropriate for PCR.

\section{Amplification PCR:}

Amplification of $16 s$ rRNA genes to confirm MTB isolates were done with specific primers shown in Table 1. mutations in the $r p o B$ gene (in common codons) were investigated in RIF resistant isolates by Multiplex PCR and using the specific primers shown in Table 1.

Amplification of the $r p o B$ gene was conducted as: an initial denaturation at $94^{\circ}$ for 5 min followed by 30 cycles of denaturation at $94^{\circ}$ for $30 \mathrm{sec}, 40 \mathrm{sec}$ of annealing and extension at $72^{\circ} \mathrm{C}$ for $50 \mathrm{sec}$ and final extension at $72^{\circ} \mathrm{C}$ for $5 \mathrm{~min}$ and reaction mixture were prepared in a total volume of $25 \mu$ l contained $2.5 \mu \mathrm{l}$ of 1 X PCR buffer, $1 \mu \mathrm{l}$ of $2 \mathrm{mM}$ dNTP, $1 \mu$ l of each primer, $0.25 \mu \mathrm{l}$ Taq DNA polymerase and $2 \mu \mathrm{l}$ of extracted DNA.

\section{RNA extraction, cDNA synthesis and reverse transcription:}

Total RNA extraction was carried out from Subcultured MTB isolates in LJ medium using QIA Gen RNA

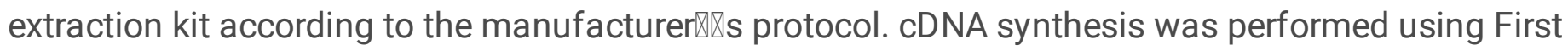
Strand cDNA synthesis kit (BIONEER, Korea) according to the manufacturer】s instructions. Then, Reverse Transcriptase-PCR was performed to assay the expression of the efflux pumps genes (tap, p55) using the primers listed in table 1 . The thermal cycling conditions included: initial denaturation at $95^{\circ} \mathrm{C}$ for $10 \mathrm{~min}$ followed by 35 cycles at $95^{\circ} \mathrm{C}$ for $35 \mathrm{sec}, 62^{\circ} \mathrm{C}$ for $30 \mathrm{sec}$ and $72^{\circ} \mathrm{C}$ for $45 \mathrm{sec}$ and the final extension at $72^{\circ} \mathrm{C}$ for $10 \mathrm{~min}$.

Quantification of gene expression using real-time quantitative PCR (qRT-PCR): 
Reaction mixtures were prepared using $12.5 \mu \mathrm{l}$ of 2 X SYBR Green master mix, $1 \mu$ l of each primer, $3 \mu \mathrm{l}$ cDNA and $7 \mu \mathrm{l}$ RNase-free water to a final volume of $25 \mu \mathrm{l}$ and the thermal cycling conditions were set at: 1 cycles of initial denaturation at $95^{\circ} \mathrm{C}$ for 2 min followed by 35 cycles of denaturation at $95^{\circ} \mathrm{C}$ for $25 \mathrm{sec}$, annealing at $62^{\circ} \mathrm{C}$ for $15 \mathrm{~min}$ and extension at $72^{\circ} \mathrm{C}$ for $15 \mathrm{~min}$ and the last step at $4^{\circ} \mathrm{C}$ for $2 \mathrm{~min}$.In this method, the expression of $16 s$ rRNA gene as a House Keeping Gene with a constant expression as control was used to compare the expression of the genes by Ratio Quantification Method and through normalization against unit mass. In this method, the initial values of the desired gene cDNA and the $16 s$ rRNA gene were determined by measuring $O D$ and from each gene were used to an equal ratio in real time PCR. After real time PCR, the Ct of control and sample gene was measured and their ratio was calculated. The standard curve line gradient for tap and $p 55$ genes and reaction efficiency was calculated by the software using the formula $\mathrm{E}=10^{(-1 \text { slope })}$. The amount of $\Delta \mathrm{Ct}$ for each gene was obtained through the

formula $\Delta \mathrm{Ct}=\mathrm{Ct}_{\text {(sample gene }- \text { control gene) }}$ and the gene ratio was calculated using the formula Ratio $=\mathrm{E}^{(\Delta \mathrm{Ct})}$.

\section{Results}

The results of drug susceptibility testing of $M$. tuberculosis isolates:

Out of 200 approved isolates as MTB, in drug sensitivity test, 67 (33.5\%) were resistant to at least one of the first line drug (EMB, STR, RIF and INH) .From 67 resistant isolates, $10(14.92 \%)$ were resistant to EMB, $21(31.34 \%)$ were resistant to STR, $28(41.79 \%)$ were resistant to INH and $23(34.33 \%)$ were resistant to RIF, 19 (28.36\%) of which were resistant to INH, in addition of FIF and were considered as multidrug resistance (MDR).

\section{The results of mutations in $r p O B$ gene in rifampin-resistant isolates:}

In the present study, PCR results revealed that $12(52.17 \%)$ isolates out of the 23 RIF resistant MTB isolates, have mutations in the $r p o B$ gene and out of them $5(41.67 \%)$ strains in codon $531,4(33.33 \%)$ in codon 526 and $3(25 \%)$ in codon 516 were mutated and were considered as RIF resistant genotypes isolates, and $11(47.83 \%)$ isolates had no mutations in these codons and were considered as resistant phenotypes and RIF sensitive genotypes isolates.

\section{Results of investigating of tap and $p 55$ genes expression in rifampin-resistant isolates by Reverse Transcriptase -PCR method:}

from all 23 RIF resistant MTB samples, 16 (69.56\%) isolates expressed tap gene, 10 (62.5\%) isolates were related to RIF resistant phenotypes and non-mutated isolates, and $6(37.5 \%)$ of them were related to RIF resistant isolates which have mutation in the rpoB gene and 15/23 (65.22\%) isolates expressed $P 55$ gene, and $9(60 \%)$ of them were related to non-mutated isolates, and $6(40 \%)$ of them were isolates which had mutations in the rpoB gene.

Results of investigating of tap and p55 genes expression level by Real time PCR method: 
considering that the reaction efficiency in this experiment was close to $100 \%$, therefore, for the genes ratio to be obtained, the reaction efficiency was considered 2 and the control $\mathrm{Ct}$ for the tap gene is 25.23 and for the $p 55$ gene, 36.76 is calculated.The threshold and standard chart of tap gene are shown in Supplements 1 and 2. Based on the results listed in the table 2, the average gene ratio of tap in nonmutated isolates was 6.85 , in RIF resistant isolates with mutation was 0.54 and in RIF sensitive isolates was $0.64(\mathrm{P}<0.05)$. The standard charts of $p 55$ gene also are shown in Supplements 3 and 4 and according to the results presented in the table 3 , the average gene ratio of $p 55$ in non-mutated isolates were 8.88 , in resistant isolates with mutation were 0.84 and in sensitive isolates were $0.85(P<0.05)$.

\section{Discussion}

The results of our study indicate that among 200 MTB clinical isolates after drug susceptibility testing, 67 (33.5\%) were resistant to at least one of the first line drugs and 23 (34.33\%) isolates were rifampin resistant, and 19 (28.36\%) were identified as MDR.

The higher prevalence of resistance to at least one of the first-line drugs and the higher prevalence of MDR in comparison with our study, were reported from India $(85.9 \%, 47.54 \%)$, Cameroon $(81.3 \%, 50 \%)$ and pakistan $(71.92 \%, 42.10 \%)$ [16]. A study of Nepal 2017 reported a relatively higher prevalence of resistance to one or more drugs (38.2\%) in comparison with our study, but the prevalence of MDR (11.7\%) and the resistance to RIF (15.7\%) were lower in their investigation than the results of our survey [17]. Also in another study in Turkey in 2010 comparing to our study, a lower rate of prevalence resistance (28.7\%), MDR (4.5\%) and resistance to RIF (6.3\%) were reported [18].

In the present study, we found that out of 23 RIF resistant isolates in the antibiotic susceptibility test, 12 $(52.17 \%)$ isolates had mutations and $11(47.83 \%)$ had no mutations in the $r p o B$ gene. In our study, the highest frequency of mutations was found in codon 531 (41.67\%), followed by that codon 526 (33.33\%) and codon $516(25 \%)$.

These findings were similar to reported results in Egypt in 2009, which the frequency rate of mutation in codons of 531,526 , and 516 , were reported $45 \%, 30 \%$ and $20 \%$, respectively. [19] Moreover, in another similar study in Vietnam the frequency of mutation were reported in codons $531(43 \%), 526(31 \%)$ and $516(15 \%)$, and it was very close to the results of our study [20].

The high frequency of mutation in codon 531 was found in previous studies in some other countries, including Indonesia (59.09\%)[21], Taiwan (68.2\%)[22], India (75.5\%)[23], Brazil (79.2\%)[24] and Tunisia (85.67)[25], which in these studies, like ours the most common mutation was reported in codon 531 However, in comparison with our study, they reported a higher prevalence of mutation in codons 53.

Many studies to date have investigated the efflux pump genes using laboratory strains such as M. bovis, M. smegmatis and the transfer of the hypothetical efflux pump genes and the use of inhibitors of the efflux pumps, and have shown that the increase of the expression level of efflux pump genes increase the level of resistance [26]. 
Also, in different studies, the importance of the efflux pumps and the role of them in the extrude of the drug have been pointed out. It has been shown that there is a direct relationship between overexpression of different genes of the efflux pumps and the resistance to various drugs in mycobacteria [27].

In the present study about the efflux pumps, the expression of the tap and $p 55$ efflux pump genes in RIF resistant MTB isolates were investigated by Reverse Transcriptase -PCR and also the level of expression of these genes were evaluated using qRT-PCR method.

The results of our study about the expression of these genes shows that out of the 23 rifampin-resistant isolates, among 11 isolates which had no mutations ( 11 non mutated isolates) in the $r p o B$ gene, 10 (90.91\%) have been expressed tap gene, and out of 12 isolates that have mutations, 6 (50\%) have been expressed tap gene. In samples with the $P 55$ efflux pump gene, $81.8 \%$ of the non-mutated isolates and $50 \%$ of the mutated isolates in the $r p o B$ gene, have been expressed the $p 55$ gene and the results of qRTPCR in our study indicate that the expression level of the tap and $p 55$ genes in resistant phenotypic and non-mutated samples compared to resistant and mutated samples and also sensitive samples were more than 10 fold and there was a significant difference in the level of expression in RIF resistant samples. This may indicate the expression of efflux pump genes in RIF resistant phenotypic isolates but had no mutation in the target genes was higher than that in resistant and mutated isolates and may be effective in resistance to this drug.

Similar studies have been done on clinical MTB isolates using qRT-PCR method, including a study by Guilian Li et al. in chine that showed out of 9 MDR isolates, 8 of them overexpressed in at least one of the 20 efflux pump genes of their investigation, and the expression level of 11 efflux pump genes out of 20 of their studied genes, including $P 55$, were significantly higher in 9 MDR isolates than that in 10 drug susceptible isolates $(P<0.05)[26]$.

In another similar study by Yamchi et al. in 2015, the expression levels of several genes, including $p 55$ and jefA, in drug-resistant and drug-sensitive MTB and H37Rv reference strains have been investigated by qRT-PCR method. They showed that out of 21 drug resistant isolates, $12(57.14 \%)$ have expressions more than 4 fold, and out of 7 isolates without any mutation in the drug target genes, $5(71.43 \%)$ had overexpression in the efflux pump. In their study, the level of expression of the efflux pump genes in drugresistant and drug sensitive samples were significantly higher than the standard strain $(P<0.05)[28]$.

Moreover, another study by Mustafa kerem calgin et al. in 2013 had been done that they reported the expression level of efflux pump genes including tap and $p 55$ were significantly higher in multidrugresistant and drug-sensitive MTB isolates compared to standard strains. But, there were no significant differences between multidrug-resistant and drug sensitive isolates [14].

A study in India by Anshika Narang et al. in 2019 have been investigated the expression of several efflux pump genes in RIF resistance and RIF susceptible MTB isolates. in their study no correlation was evident between examined efflux pumps and RIF resistance although their study limited to a small number of clinical isolates, overexpression of 2 genes from tested efflux pumps genes ( $m m p L 5$ and Rv0194) in a 
greater number of RIF resistant isolates as compared to RIF susceptible isolates suggests a role in RIF resistance[29].

Another study by Ke Wang et al. in 2013 have been investigated the expression profile of ABC efflux pumps (Rv1217c and Rv1218c) by RT-qPCR in MDR M. tuberculosis clinical isolates in china. They demonstrated that expression levels of Rv1217c and Rv1218c increased 3.1 and 5.4 fold in MDR isolates compared to drug susceptible isolates [30].

\section{Conclusions}

In the present study, out of 23 RIF resistant isolates, 11 (47.83\%) had no mutations in the rpoB gene, which could indicate the role of other mechanisms such as efflux Pump systems. According to the results of our study, the expression level of the studied efflux pump genes in resistant and non-mutated MTB isolates was significantly higher than mutated isolates and susceptible isolate. The results increase the likelihood of this hypothesis that in isolates with phenotypic resistance but not mutations in the drug target genes, it may be that the afflux pumps to be effective in resistance, although determining its roles requires further studies and the evaluation of the phenotypic activity of these pumps.

\section{Abbreviations}

TB: Tuberculosis; WHO: World Health Organization; MDR-TB: multidrug resistant tuberculosis; INH: isoniazid; RIF: rifampin; RRDR: Rifampin resistance determining region.

\section{Declarations}

\section{Acknowledgements}

None.

\section{Authors' contributions}

Conceptualisation: FK, NH, MSSA; Methodology: FK, MSSA, NH, ZZ; Formal

analysis and investigation: $\mathrm{FK}, \mathrm{NH}$; Writing (original draft preparation): MSSA,

ZZ; Writing (review and editing): FK, MSSA, NH, FA, ZZ; Resources: MSSA; Supervision: NH. The author(s) read and approved the final manuscript.

\section{Funding}

None to declare.

\section{Availability of data and materials}


All relevant data are included in the manuscript.

\section{Ethics approval and consent to participate}

Not applicable.

\section{Consent for publication}

Not applicable.

\section{Competing interests}

None of the authors have any competing interests.

\section{Author details}

${ }^{1}$ Department of Bacteriology and Virology, School of Medicine, Shiraz University of Medical Sciences, Shiraz, Iran. ${ }^{2}$ Department of Microbiology and Immunology, Cellular and Molecular Research Center, Basic Health Sciences Institute, Shahrekord University of Medical Sciences, Shahrekord, Iran.

${ }^{3}$ Bioinformatics and Computational Biology Research Center, Shiraz University of Medical Sciences, Shiraz, Iran. ${ }^{4}$ Pulmonary Research Center, TB Laboratory, Shiraz University of Medical Sciences, Shiraz, Iran.

\section{References}

1. Banik A, Das N, Lyngdoh VW, Phukan AC, Dutta V: Prevalence and first-line drug sensitivity trends of Mycobacterium tuberculosis at a tertiary center in North-East India. The Egyptian Journal of Chest Diseases and Tuberculosis 2018, 67(1):32.

2. Harding E: WHO global progress report on tuberculosis elimination. The Lancet Respiratory Medicine 2020, 8(1):19.

3. Prim RI, Schörner MA, Senna SG, Nogueira CL, Figueiredo ACC, Oliveira JGd, Rovaris DB, Bazzo ML: Molecular profiling of drug resistant isolates of Mycobacterium tuberculosis in the state of Santa Catarina, southern Brazil. Memórias do Instituto Oswaldo Cruz 2015, 110(5):618-623.

4. Otu A, Umoh V, Habib A, Ameh S, Lawson L, Ansa V: Drug resistance among pulmonary tuberculosis patients in Calabar, Nigeria. Pulmonary medicine 2013, 2013.

5. Cole ST: Mycobacterium tuberculosis: drug-resistance mechanisms. Trends in microbiology 1994, 2(10):411-415.

6. Schön T, Miotto P, Köser CU, Viveiros M, Böttger E, Cambau E: Mycobacterium tuberculosis drugresistance testing: challenges, recent developments and perspectives. Clinical Microbiology and Infection 2017, 23(3):154-160. 
7. Palomino JC, Martin A: Drug resistance mechanisms in Mycobacterium tuberculosis. Antibiotics 2014, 3(3):317-340.

8. Erawati M, Andriany M, Kusumaningrum NS: Mutations in the RpoB Gene of Multidrug-Resistant Mycobacterium Tuberculosis Isolates from Semarang, Indonesia. International Journal of Molecular and Clinical Microbiology 2017, 7(2):816-823.

9. Pang Y, Lu J, Wang Y, Song Y, Wang S, Zhao Y: Study of the rifampin monoresistance mechanism in Mycobacterium tuberculosis. Antimicrobial agents and chemotherapy 2013, 57(2):893-900.

10. da Silva PEA, Von Groll A, Martin A, Palomino JC: Efflux as a mechanism for drug resistance in Mycobacterium tuberculosis. FEMS Immunology \& Medical Microbiology 2011, 63(1):1-9.

11. Ramón-García S, Mick V, Dainese E, Martín C, Thompson CJ, De Rossi E, Manganelli R, Aínsa JA: Functional and genetic characterization of the tap efflux pump in Mycobacterium bovis BCG. Antimicrobial agents and chemotherapy 2012, 56(4):2074-2083.

12. Rodrigues $L$, Villellas $C$, Bailo $R$, Viveiros $M$, Aínsa JA: Role of the Mmr efflux pump in drug resistance in Mycobacterium tuberculosis. Antimicrobial agents and chemotherapy 2013, 57(2):751-757.

13. Sun J, Deng Z, Yan A: Bacterial multidrug efflux pumps: mechanisms, physiology and pharmacological exploitations. Biochemical and biophysical research communications 2014, 453(2):254-267.

14. Calgin MK, Sahin F, Turegun B, Gerceker D, Atasever M, Koksal D, Karasartova D, Kiyan M: Expression analysis of efflux pump genes among drug-susceptible and multidrug-resistant Mycobacterium tuberculosis clinical isolates and reference strains. Diagnostic microbiology and infectious disease 2013, 76(3):291-297.

15. !!! INVALID CITATION !!! [19-22].

16. !!! INVALID CITATION !!! [24-26].

17. Maharjan S, Singh A, Khadka D, Aryal M: Drug resistance pattern in pulmonary tuberculosis patients and risk factors associated with multi-drug resistant tuberculosis. Journal of Tuberculosis Research 2017, 5(2):106-117.

18. Agarwal M, Gunal S, Durmaz R, Yang Z: Integration of Mycobacterium tuberculosis drug susceptibility testing and genotyping with epidemiological data analysis to gain insight into the epidemiology of drug-resistant tuberculosis in Malatya, Turkey. Journal of clinical Microbiology 2010, 48(9):3301-3305.

19. Abdelaal A, Abd El-Ghaffar H, Zaghloul MHE, Badran E, Fathy A: Genotypic detection of rifampicin and isoniazid resistant Mycobacterium tuberculosis strains by DNA sequencing: a randomized trial. Annals of Clinical Microbiology and Antimicrobials 2009, 8(1):4.

20. Caws M, Duy PM, Tho DQ, Lan NTN, Farrar J: Mutations prevalent among rifampin-and isoniazidresistant Mycobacterium tuberculosis isolates from a hospital in Vietnam. Journal of clinical microbiology 2006, 44(7):2333-2337.

21. Rosilawati ML, Yasmon A: Detection of multidrug-resistant Mycobacterium tuberculosis directly from sputum samples of patients from Jakarta, Indonesia by radioisotope-based PCR-dot blot 
hybridization. Southeast Asian Journal of Tropical Medicineand Public Health 2012, 43(1):89.

22. Hwang H-Y, Chang C-Y, Chang L-L, Chang S-F, Chang Y-H, Chen Y-J: Characterization of rifampicinresistant Mycobacterium tuberculosis in Taiwan. Journal of medical microbiology 2003, 52(3):239245.

23. Mani C, Selvakumar N, Narayanan S, Narayanan P: Mutations in the rpoB gene of multidrug-resistant Mycobacterium tuberculosis clinical isolates from India. Journal of clinical microbiology 2001, 39(8):2987-2990.

24. Valim ARM, Rossetti MLR, Ribeiro MO, Zaha A: Mutations in the rpoB gene of multidrug-resistant Mycobacterium tuberculosis isolates from Brazil. Journal of clinical microbiology 2000, 38(8):31193122.

25. Soudani A, Hadjfredj S, Zribi M, Masmoudi A, Messaoud T, Tiouri H, Fendri C: Characterization of Tunisian Mycobacterium tuberculosis rifampin-resistant clinical isolates. Journal of clinical microbiology 2007, 45(9):3095-3097.

26. Li G, Zhang J, Guo Q, Jiang Y, Wei J, Zhao L-I, Zhao X, Lu J, Wan K: Efflux pump gene expression in multidrug-resistant Mycobacterium tuberculosis clinical isolates. PloS one 2015, 10(2):e0119013.

27. Ramón-García S, Martín C, Thompson CJ, Aínsa JA: Role of the Mycobacterium tuberculosis P55 efflux pump in intrinsic drug resistance, oxidative stress responses, and growth. Antimicrobial agents and chemotherapy 2009, 53(9):3675-3682.

28. Yamchi JK, Haeili M, Feyisa SG, Kazemian H, Shahraki AH, Zahednamazi F, Fooladi AAI, Feizabadi MM: Evaluation of efflux pump gene expression among drug susceptible and drug resistant strains of Mycobacterium tuberculosis from Iran. Infection, Genetics and Evolution 2015, 36:23-26.

29. Narang A, Garima K, Porwal S, Bhandekar A, Shrivastava K, Giri A, Sharma NK, Bose M, Varma-Basil $M$ : Potential impact of efflux pump genes in mediating rifampicin resistance in clinical isolates of Mycobacterium tuberculosis from India. PloS one 2019, 14(9):e0223163.

30. Wang K, Pei H, Huang B, Zhu X, Zhang J, Zhou B, Zhu L, Zhang Y, Zhou F-F: The expression of ABC efflux pump, Rv1217c-Rv1218c, and its association with multidrug resistance of Mycobacterium tuberculosis in China. Current microbiology 2013, 66(3):222-226.

31. Allegui Z, Ghariani A, Draoui H, Ghezal A, Mehiri E, Slim-Saidi L: Detection of isoniazid and rifampin resistance of Mycobacterium tuberculosis by a multiplex allele-specific polymerase chain reaction (PCR) assay. International journal of mycobacteriology 2012, 1(1):34-39.

\section{Tables}

Table 1. Primers used in PCR reaction 


\begin{tabular}{|c|c|c|c|}
\hline Target & Primer sequence & Size of product & Reference \\
\hline 16s rRNA-F & 5' CTT AAC ACA TGC AAG TCG AAC 3' & 280 & \multirow[t]{2}{*}{ [14] } \\
\hline 16s rRNA-R & 5' GTA TCT CAG TCC CAG TGT G 3' & & \\
\hline rpoB516 & CAGCTGAGCCAATTCATGGA & 218 & \multirow[t]{4}{*}{ [31] } \\
\hline гроB526 & CTGTCGGGGTTGACCCA & 185 & \\
\hline гроB531 & CACAAGCGCCGACTGTC & 170 & \\
\hline RIRm & TTGACCCGCGCGTACAC & & \\
\hline Rv1258c-F & 5’AGT TAT AGA TCG GCT GGA TGG 3' & 255 & \multirow[t]{2}{*}{ [14] } \\
\hline Rv1258c-R & 5'AAT ACT TCA CCG ACC ACC AGC AAC 3' & & \\
\hline Rv1410c-F & 5’TCT TGG ACT TCC GGT TCA TC 3' & 221 & [14] \\
\hline Rv1410c-R & 5’TAC CGG TTC AAC CAG ATC CTG 3' & & \\
\hline
\end{tabular}

Table 2: results of real time PCR (tap gene)

\begin{tabular}{|c|c|c|c|c|}
\hline tap gene & Number & $\mathrm{Ct}$ & $\Delta \mathrm{Ct}=\mathrm{Ct}_{\mathrm{s}}-\mathrm{Ct}_{\mathrm{c}}$ & Ratio $=\mathrm{E}^{(\Delta \mathrm{Ct})}$ \\
\hline \multirow[t]{6}{*}{ Non mutated MTB isolates } & 1 & 28.15 & 2.92 & 7.57 \\
\hline & 2 & 28.21 & 2.98 & 7.89 \\
\hline & 3 & 28.34 & 3.11 & 8.63 \\
\hline & 4 & 27.64 & 2.41 & 5.31 \\
\hline & 5 & 27.51 & 2.28 & 4.86 \\
\hline & & 27.97 & 2.74 & 6.85 \\
\hline \multirow[t]{6}{*}{ Resistant MTB isolates had mutation in $r p o B$} & 6 & 23.73 & -1.50 & 0.35 \\
\hline & 7 & 23.87 & -1.36 & 0.39 \\
\hline & 8 & 24.46 & -0.77 & 0.59 \\
\hline & 9 & 24.60 & -0.36 & 0.65 \\
\hline & 10 & 25.70 & -0.47 & 0.72 \\
\hline & & 24.47 & -0.95 & 0.54 \\
\hline Sensitive isolate & 11 & 24.58 & -0.65 & 0.64 \\
\hline
\end{tabular}

Table 3: results of real time PCR ( $p 55$ gene) 


\begin{tabular}{|c|c|c|c|c|}
\hline P55 gene & $\begin{array}{l}\text { Number of } \\
\text { isolate }\end{array}$ & $\mathrm{Ct}$ & $\begin{array}{l}\Delta \mathrm{Ct}=\mathrm{Ct}_{\mathrm{s}}- \\
\mathrm{Ct}_{\mathrm{c}}\end{array}$ & Ratio $=\mathrm{E}^{(\Delta \mathrm{Ct})}$ \\
\hline \multirow[t]{5}{*}{ Non mutated MTB isolates } & 1 & 40.16 & 3.4 & 10.56 \\
\hline & 2 & 39.97 & 3.21 & 9.25 \\
\hline & 3 & 39.86 & 3.10 & 8.57 \\
\hline & 4 & 39.80 & 3.04 & 8.22 \\
\hline & 5 & 39.72 & 2.96 & 7.78 \\
\hline Average & & 39.90 & 3.14 & 8.88 \\
\hline \multirow{5}{*}{$\begin{array}{l}\text { Resistant MTB isolates have mutation in } \\
r p o B\end{array}$} & 6 & 36.58 & -0.18 & 0.88 \\
\hline & 7 & 36.62 & -0.14 & 0.91 \\
\hline & 8 & 36.67 & -0.09 & 0.93 \\
\hline & 9 & 37.15 & -0.39 & 0.76 \\
\hline & 10 & 37.23 & -0.47 & 0.72 \\
\hline Average & & 36.85 & -0.25 & 0.84 \\
\hline Sensitive isolate & 11 & 36.53 & -0.23 & 0.85 \\
\hline
\end{tabular}

\section{Supplementary Files}

This is a list of supplementary files associated with this preprint. Click to download.

- supplements.docx 